\title{
Primary Non-Hodgkin lymphoma of the tongue with cervical lymph node involvement: A rare presentation masquerading squamous cell carcinoma
}

\author{
Akanksha Bhatia ${ }^{1}$, Prajwala Gupta ${ }^{2}$, Swasti Jain ${ }^{1}$, Devender Singh Chauhan ${ }^{3}$, Minakshi Bhardwaj ${ }^{2}$ \\ From ${ }^{1}$ Senior Resident, ${ }^{2}$ Professor, ${ }^{3}$ Consultant Pathologist, Department of Pathology, Atal Bihari Vajpayee Institute of Medical Sciences, Dr. Ram \\ Manohar Lohia Hospital, New Delhi, India
}

\begin{abstract}
Primary non-Hodgkin lymphoma (NHL) of the tongue is extremely rare. We present here a case of primary diffuse large B cell NHL, non-germinal center type in a 60-year-old female, who presented with a mass in the base of the tongue and vallecula with cervical lymphadenopathy. Clinically, a diagnosis of squamous cell carcinoma was kept. Fine-needle aspiration cytology was useful in the early diagnosis of the intraoral NHL involving a cervical lymph node.
\end{abstract}

Key words: Fine-needle aspiration cytology, Intraoral, Lymphoma, Tongue

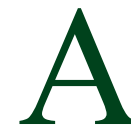

lthough non-Hodgkin lymphoma (NHL) of the oral cavity is rare, it constitutes the third most common cause of malignancy of the oral cavity after squamous cell carcinoma (SCC) and salivary gland neoplasm [1]. NHL of the oral cavity constitutes $2 \%$ of all the extranodal NHLs [2]. In the oral cavity, it generally arises from the Waldeyer's ring, and its location in the tongue is extremely rare [3]. Hence, fine-needle aspiration cytology (FNAC) in such cases can be extremely useful in the early diagnosis of an unsuspected NHL. We present here a case of primary intraoral NHL which clinically mimicked SCC presenting as a lesion in the base of the tongue with cervical lymph node involvement.

\section{CASE REPORT}

A 60-year-old female presented with swelling in the left cervical region for 1 month. She also complained of difficulty in swallowing and change in voice for 20 days. On examination, her vitals were normal, and there was no pallor, icterus, cyanosis, or edema. Lymphadenopathy was noted in the left upper and lower cervical region. The lymph nodes were multiple, matted, firm, and altogether measuring $2.5 \mathrm{~cm} \times 2.5 \mathrm{~cm}$. On oral examination, a soft mass was seen in the base of the tongue and vallecula over the left side.

Contrast-enhanced computed tomography showed a welldefined lobulated heterogeneously enhancing soft-tissue mass involving the left glossotonsillar sulcus extending into the left parapharyngeal wall (Fig. 1). Multiple enlarged heterogeneously

\section{Access this article online}

Received - 30 August 2020

Initial Review - 14 September 2020

Accepted - 14 October 2020

DOI: $10.32677 /$ IJCR.2020.v06.i10.012 enhancing cervical lymph nodes were also noted in the left cervical region. Fine-needle aspiration was done from the left cervical lymph node. Smears were highly cellular and revealed atypical intermediate to large-sized mononuclear lymphoid cells (Fig. 2a). These cells had a scant to moderate amount of pale cytoplasm with evidence of cytoplasmic vacuolation. Nucleus showed mild-tomoderate anisonucleosis with nuclear indentation and convolution, granular chromatin, and prominent 1-2 nucleoli. Based on these findings, a cytological diagnosis of large cell NHL was given.

A biopsy was done from the base of the tongue lesion, which showed sheets of atypical large lymphoid cells (Fig. 2b). These cells were round with vesicular nuclei, prominent nucleoli, and scant to moderate amount of cytoplasm. Immunohistochemistry (IHC) showed diffuse positivity for CD20 and MUM1 (Fig. 2c and 2d). CD3, CD10, and BCL6 were negative. Based on these morphological and IHC findings, a final diagnosis of diffuse large B cell lymphoma (DLBCL) of non-germinal center type was given. Following this, the patient was advised a wide local excision. Unfortunately, the patient was lost to follow-up.

\section{DISCUSSION}

The incidence oflymphomas in the oral cavity is rare, accounting for $3-5 \%$ of all malignancies, despite it being the third most common malignancy following SCC and salivary gland neoplasms [1]. The head and neck region is the second most common site for extranodal NHL after the gastrointestinal tract [3]. Among the intraoral lymphomas, the NHL of the tongue is extremely rare.

Correspondence to: Dr. Prajwala Gupta, Room No. 305, $3^{\text {rd }}$ floor, OPD building, ABVIMS, Dr. Ram Manohar Lohia Hospital, Baba Kharak Singh Marg, New Delhi - 110 001, India. E-mail: prajwalagupta@gmail.com

(C) 2020 Creative Commons Attribution-NonCommercial 4.0 International License (CC BY-NC-ND 4.0). 


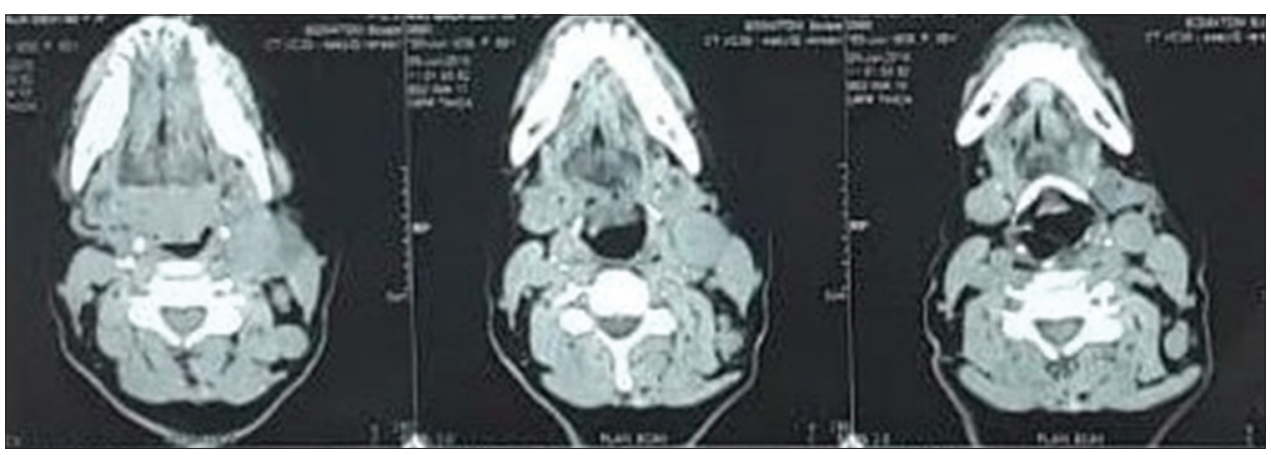

Figure 1: Contrast-enhanced computed tomography showing a well-defined heterogeneously enhancing soft-tissue mass involving the left glossotonsillar sulcus, extending into the left parapharyngeal wall

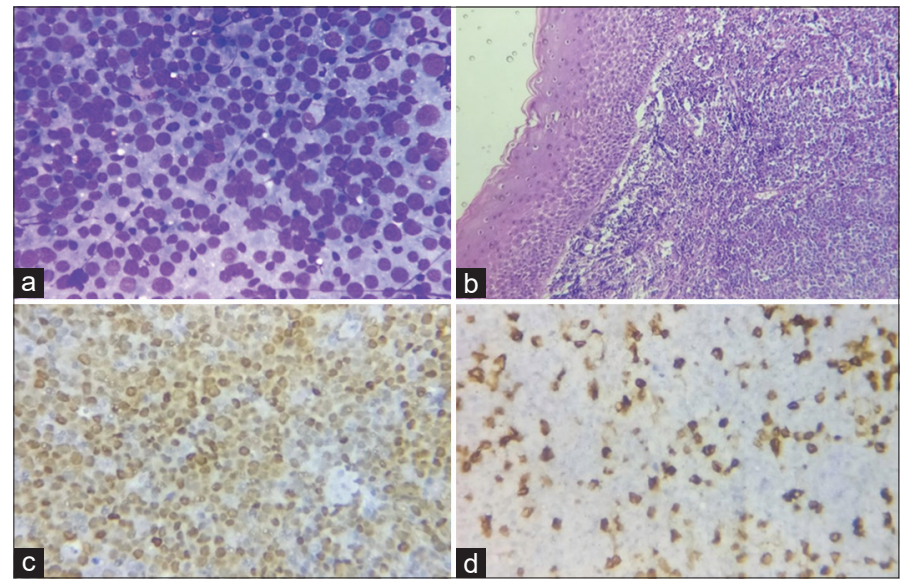

Figure 2: (a) Fine-needle aspiration smear showing the dual population of cells composed of atypical lymphoid cells and mature lymphocytes (Giemsa; ×400); (b) Section from biopsy showing sheets of atypical large lymphoid cells (hematoxylin and eosin; $\times 100$ ); (c) CD20 positivity in atypical lymphoid cells $(\mathrm{DAB} ; \times 400)$; and (d) many cells reveal MUM1 positivity $(\mathrm{DAB} ; \times 400)$

The most common location of the NHL in the oral cavity is the Waldeyer's lymphatic ring $[4,5]$. Waldeyer's ring is composed of the lymphoid tissue present in the nasopharynx and oropharynx and includes the adenoids, tubal tonsils, palatine tonsils, lymphoid tissue of the soft palate, and base of the tongue (lingual tonsil) [6]. Palatine tonsils are the commonest predilection site for the NHL in the Waldeyer's ring and involvement of the base of the tongue is rare [5].

There is little literature about the etiological factors for lymphomas of the oral cavity. Few cases of lymphoma of the oral cavity have been reported in association with acquired immunodeficiency syndrome (AIDS) [1]. Another hypothesis suggests that they develop as a result of imbalanced immunoregulation, as few and certain lymphomas were associated with AIDS [7]. However, in the majority of cases, no overt immunologic abnormality is noted. Furthermore, there are studies linking the role of viruses to lymphomas in animals, but the same studies have failed to document the same in human NHLs [7].

Head and neck lymphomas differ from other lymphomas with their higher incidence of extranodal presentation and better prognosis. Common presenting symptoms are swelling, pain, or discomfort due to mass effect, ulceration, and sometimes may even cause difficulty in speech, dysphagia, or odynophagia $[3,5]$. Awareness of this clinical entity in the oral region is important because lymphomas and more common malignant lesions such as SCC cannot be differentiated clinically.

Other differential diagnoses also include metastatic tumors of the tongue, malignant melanoma, poorly differentiated adenocarcinoma, and other rare tumors such as neuroblastoma, rhabdomyosarcoma, and Ewing's sarcoma [8]. Hence, FNAC plays an important role in such cases. Most of the head and neck NHL, including oral cavity lymphomas, are of B cell origin, with diffuse large B cell type being the most common [9]. In cases of DLBCLs, the revised WHO lymphoma classification advises the use of the Hans algorithm [10].

The algorithm is based on IHC expressions of CD10, BCL6, and MUM1 proteins. According to this, DLBCLs are classified into germinal center B-cell-like (GCB) group, activated B-cell-like (ABC) group (or the non-germinal center type), and type 3 group. GCB shows high expression of germinal center B-cell signature genes such as CD10 expression, BCL2 gene rearrangement, or REL amplification, with an expression of $\mathrm{CD} 10$ on IHC. ABC group or the non-germinal center type expresses genes normally induced during in vitro activation of peripheral blood B lymphocytes, expressing MUM1 on IHC, with the presence of BCL6 translocation and activation of NF- $\mathrm{\kappa B}$. The non-germinal center type, which was seen in the present case, is usually associated with lower survival rates as compared to the GCB type.

On histopathology, the differential diagnosis of discrete immature round cells at this site are rhabdomyosarcoma, peripheral neuroectodermal tumors, and small cell carcinoma of the tongue [7]. However, these tumors are extremely rare and in the present case, characteristic morphological features and IHC were diagnostic of the NHL.

Management of the lymphomas is usually by wide local excision followed by chemotherapy and radiotherapy. The majority of patients of non-germinal center DLBCL are usually treated with rituximab, cyclophosphamide, doxorubicin, vincristine, and prednisone [11]. However, novel agents are also being investigated, which include bortezomib, lenalidomide, and ibrutinib [12-14]. The prognosis of NHL is related to the stage of 
the tumor, the aggressiveness of the tumor cells, and the response to treatment [1].

\section{CONCLUSION}

The primary NHL of the base of the tongue is extremely rare. Till date, few cases of NHL of the base of the tongue have been reported in the literature. It is a clinical mimicker of the commoner intraoral malignancy (SCC), and FNAC of the cervical lymph node may help in early diagnosis of this unsuspected lymphoma.

\section{REFERENCES}

1. Vaswani B, Shah M, Shah PM, Parikh BJ, Anand AS, Sharma G. NonHodgkin's lymphoma of tongue-a case report. Indian J Med Paediatr Oncol 2008;29:58-61.

2. Shah GH, Panwar SK, Chaturvedi PP, Kane SN. Isolated primary extranodal lymphoma of the oral cavity: A series of 15 cases and review of literature from a tertiary care cancer centre in India. Indian J Med Paediatr Oncol 2011;32:76-81.

3. Singh A, Sood N, Kaur H, Garg B, Munjal M. Primary diffuse large $\mathrm{B}$ cell lymphoma of the base of tongue: A rare entity. Am J Otolaryngol 2014;35:435-8.

4. Hmidi M, Touiheme N, Elboukhari A, Kettani M, Elmejareb C, Messary A. Primary B cell lymphoma of the tongue: A case report. Pan Afr Med J 2012;12:5.

5. Simsek E, Ozmen HK, Bilen Y, Calik M, Gündogdu B, Erdemci B. Cystic isolated lymphoma of the base of the tongue: A case report. Oncol Lett 2016;11:2539-41.

6. Divyambika CV, Satish Srinivas K, Shanmugam S. Non Hodgkin's lymphoma involving base of tongue. J Indian Acad Oral Med Radiol 2011;23:627-9.

7. Murthy S, Panduranga C. Fine-needle aspiration diagnosis of extranodal
non-Hodgkin's lymphoma of the tongue. J Cytol 2011;28:81-3.

8. Terada T. Primary non-Hodgkin B-cell lymphoma of the tongue. Br J Oral Maxillofac Surg 2011;49:e18-9.

9. Shima N, Kobashi Y, Tsutsui K, Ogawa K, Maetani S, Nakashima Y, et al. Extranodal non-Hodgkin's lymphoma of the head and neck. A clinicopathologic study in the Kyoto-Nara area of Japan. Cancer 1990;66:1190-7.

10. Swerdlow SH, Campo E, Pileri SA, Harris NL, Stein H, Siebert R, et al. The 2016 revision of the World Health Organization classification of lymphoid neoplasms. Blood 2016;127:2375-90.

11. Tilly H, Gomes da Silva M, Vitolo U, Jack A, Meignan M, Lopez-Guillermo A, et al. Diffuse large B-cell lymphoma (DLBCL): ESMO clinical practice guidelines for diagnosis, treatment and follow-up. Ann Oncol 2015;26:v116-25.

12. Ruan J, Martin P, Furman RR, Lee SM, Cheung K, Vose JM, et al. Bortezomib plus CHOP-rituximab for previously untreated diffuse large B-cell lymphoma and mantle cell lymphoma. J Clin Oncol 2011;29:690-7.

13. Nowakowski GS, LaPlant B, Macon WR, Reeder CB, Foran JM, Nelson GD, et al. Lenalidomide combined with $\mathrm{R}-\mathrm{CHOP}$ overcomes negative prognostic impact of non-germinal center B-cell phenotype in newly diagnosed diffuse large B-Cell lymphoma: A phase II study. J Clin Oncol 2015;33:251-7.

14. Younes A, Thieblemont C, Morschhauser F, Flinn I, Friedberg JW, Amorim S, et al. Combination of ibrutinib with rituximab, cyclophosphamide, doxorubicin, vincristine, and prednisone (R-CHOP) for treatment-naive patients with CD20-positive B-cell non-Hodgkin lymphoma: A nonrandomised, phase 1b study. Lancet Oncol 2014;15:1019-26.

Funding: None; Conflicts of Interest: None Stated.

How to cite this article: Bhatia A, Gupta P, Jain S, Chauhan DS, Bhardwaj M. Primary Non-Hodgkin lymphoma of the tongue with cervical lymph node involvement: A rare presentation masquerading squamous cell carcinoma. Indian J Case Reports. 2020;6(10):580-582. 